\title{
Mode I Fracture Toughness of Aerospace Polymer Composites Exposed to Fresh and Salt Water
}

\author{
André Couture ${ }^{1}$, Jeremy Laliberte ${ }^{1, *}$, Chun $\mathrm{Li}^{2}$ \\ 1Department of Mechanical and Aerospace Engineering, Carleton University, Ottawa, ON K1S 5B6 \\ ${ }^{2}$ Aerospace Portfolio, National Research Council Canada, 1200 Montreal Rd., Ottawa ON K1A 0R6 \\ *Corresponding Author: jeremy.laliberte@carleton.ca
}

Copyright (C) 2013 Horizon Research Publishing All rights reserved.

\begin{abstract}
With the increasing use of polymer matrix composites (PMCs) in aircraft structures, there is a need to improve the understanding of the long-term environmental durability of these advanced materials. Unlike metals, where one of the primary mechanisms of degradation is corrosion, polymer composite structures are susceptible to environmental degradation in different ways. In order to better understand these effects, an investigation into the influence of temperature, humidity and salinity on Mode I fracture toughness of adhesively bonded joints in PMCs was carried out. The objective of this study was to build an improved understanding of composite degradation mechanisms that may affect long-term performance of composite structures. Double Cantilever Beam (DCB) specimens were manufactured by bonding carbon fibre/epoxy laminates with epoxy film adhesive and then exposed to seven different environmental conditions including. The Mode I strain energy release rate, $G_{I C}$, was measured and the effect of different conditions on the disband behavior was identified.
\end{abstract}

Keywords Polymer composite, salt water exposure, mode I fracture toughness, bonded joints

\section{Introduction}

Polymer matrix composites (PMCs) have found increasing use in the aerospace industry due to potential benefits that they offer when compared to metals, such as reduced part count, lower weight and improved fatigue performance [1],[2]. Unlike engineering alloys, which have been the subject of intense study for centuries, polymers and modern composites have only a recent history of engineering applications, which is generally considered to have started around 1942, when the first fibreglass boat was built [2]. Due to the relative novelty of polymer matrix composites, and the differences between their behaviour and that of metals, research into how they degrade during long term exposure to the environment is required.
For metallic parts, many models exist which can be used to predict the life of the components in service. For example, linear elastic fracture mechanics allows designers to: 1) evaluate the residual strength of metallic components containing cracks, 2) predict the rate of propagation of cracks due to fatigue loading of a component and 3) account for factors such as corrosive environments [3]. The alloys used in aerospace applications, as well as joints that are welded, bolted and riveted, have been thoroughly studied and their properties and design requirements are now well established [4]-[6].

On the other hand, PMCs can behave in markedly different ways as compared to metals. While PMCs are generally considered to be resistant to fatigue crack propagation [7], it is also well-known that their mechanical and physical properties may change when exposed to high temperatures and humidity. For instance, one change in mechanical properties occurs at the glass transition temperature, $T_{g}$, at which many polymers change from a glass-like to a rubber-like solid [7]. Over time, polymers used extensively in their glass-like state will age as a result of random molecular motion which modifies the configurations of the polymer chains to more stable arrangements since the original unstable configuration was achieved by rapidly cooling the polymer to below its $T_{g}$ [6]. High temperatures - i.e. temperatures near but still below the $T_{g}$ of the polymer - accelerate this aging process [7],[8]. Aging can be reversed by heating polymers above their $T_{g}$ and quenching them again [8]. There are also irreversible high-temperature degradation mechanisms such as thermo-oxidative reactions which can occur in the presence of oxygen. For instance, studies using Fourier Transform Infrared spectroscopy identified irreversible chemical changes in epoxy at temperatures as low as $70^{\circ} \mathrm{C}$ [9][10].

High temperatures have also been found to accelerate the diffusion of moisture into polymers that are subjected to humid conditions [11]-[13]. There is still considerable uncertainty as to the specific interactions between water molecules and polymer chains [14]. However, one specific macroscopic property change that is commonly observed is plasticization, which is observable as a lowering of the 
polymer's $T_{g}$. More thorough reviews of this subject are available in [14],[15]. It should be noted that upon drying, plasticization is reversed and the initial $T_{g}$ can be recovered. In contrast, irreversible degradation of polymers has been reported in the form of hydrolysis of the backbone of epoxy chains [16],[17]. Finally, changes in the failure mode of adhesively-bonded specimens have been observed, with moisture often changing the failure mode from cohesive (failure within the adhesive layer) to adhesive (failure between the adhesive layer and the substrate) [18]-[20]. Relatively few studies have been conducted to examine such behaviour specifically for PMCs that are bonded to each other [21]-[23]. Other researchers have examined the effect of environmental conditioning on mechanical performance and noted the sensitivity of the results to variations in the conditions used [24].

Another rarely-studied environmental variable for aerospace PMCs has been the influence of salinity, which is of interest in certain aerospace applications such as search and rescue (SAR), maritime patrol, and carrier-based aircraft. One observed effect of salt ions in water was the reduction of the rate of moisture diffusion into a polymer when compared to distilled water [25]. Conditioning in salt water actually slowed the degradation of the interlaminar shear strength of a composite laminate, but for a given water content, the results were the same [25]. No studies were found which included typical aerospace composite materials, salt water conditioning and Mode I fracture toughness tests. However, studies into the effect of salinity on bonded aluminium substrates have taken place which showed a loss of joint strength due to corrosion of the metal substrates. Unfortunately, they did not provide clear conclusions on the effect of salinity on the adhesive itself [26],[27].

The focus of the present study is on the effects of moisture on the Mode I fracture of adhesively bonded Double Cantilever Beam (DCB) specimens manufactured from aerospace-grade, autoclave-cured carbon fibre/epoxy laminates. This paper includes discussions on the design of the test matrix, specimen manufacturing and environmental conditioning procedures, DCB testing, data analysis, results and discussion, followed by conclusions. We focus on a novel comparison of the effects of fresh water versus salt water and also immersion versus vapour expsosure under differing temperature conditions. By using a well-understood test method (double cantilever beam) we reduced experimental uncertainties and possible sources of error. The results of this study provide a unique insight into the behavior of bonded aerospace composites under a range of representative service conditions.

\section{Experimental Methodology}

\subsection{Test Matrix and Specimen Manufacturing}

The specimens were manufactured in three major steps.
First, 13-ply unidirectional carbon fibre-epoxy laminates were laid up and cured into $216 \times 356 \mathrm{~mm}^{2}$ panels from Cycom 5276-1 toughened epoxy pre-preg (preimpregnated carbon fibre-reinforced epoxy) supplied by Cytec. The cure cycle featured a single temperature/pressure step to $177^{\circ} \mathrm{C}$ and $586 \mathrm{kPa}$. Following the recommended cure cycle from the material supplier. Following a non-destructive inspection, the acceptable laminates were surface-dried for 2 hours in an oven at $80^{\circ} \mathrm{C}$, wiped with a solvent, grit-blasted, then bonded with two layers of AF 163-2K separated by a $0.01 \mathrm{~mm}$ thick Teflon insert over a 140 x 216 $\mathrm{mm}^{2}$ area in the middle of the panel.

The adhesive was cured in two steps: the first was at $95^{\circ} \mathrm{C}$ and $345 \mathrm{kPa}$ for 20 minutes, and the second at $121^{\circ} \mathrm{C}$ and $345 \mathrm{kPa}$ for 70 minutes; the first step was to allow the excess adhesive to flow out and reduce the overall bondline thickness to values more representative of real applications, where 0.13-0.26 mm thick bondlines are often considered optimal [28]. Each panel was given a batch letter and panel number based on the bonding step (e.g. C01- $\mathrm{C} 04$ were four different panels bonded at the same time). Third, the bonded panels were cut and hinges were bonded to them with Hysol EA 9360 paste adhesive, as shown in Fig. 1. The specimens were then conditioned under several environments, as described below.

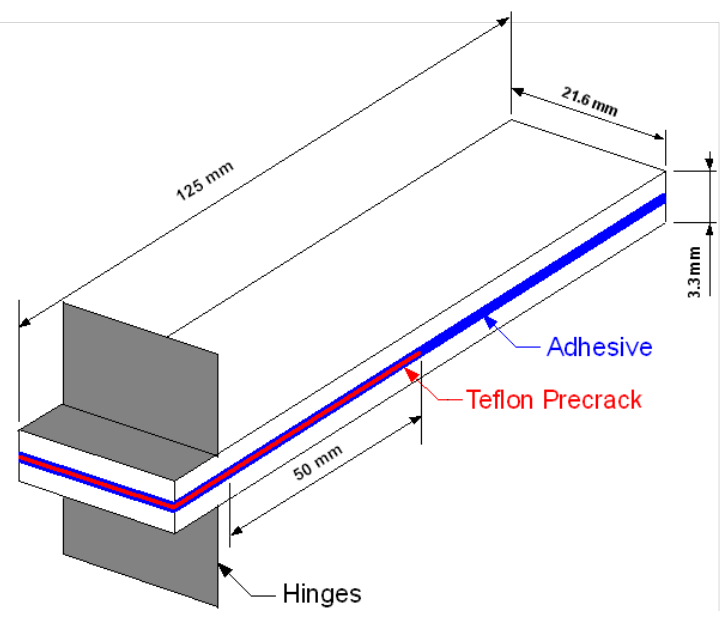

Figure 1. Double cantilever beam (DCB) specimen design.

\subsection{Environmental Conditioning}

Seven conditions were selected for the DCB specimens as outlined in Table 1. The first was a reference called Room Temperature Ambient humidity (RTA), and the others involved two temperatures (Intermediate $=70^{\circ} \mathrm{C}$, High $=82^{\circ} \mathrm{C}$ ), two forms of exposure to moisture (Vapour and Immersion), two salinities (fresh Water and Salt water at $24.5 \mathrm{~g} \mathrm{NaCl}$ per $\mathrm{L}$ of water) and freeze-thaw cycling (indicated by a "Yes" or "No" in the fourth position in the naming convention). To achieve all but the salt water environments, the specimens were placed in commercial temperature-humidity test chambers, which held the specimens at the specified temperature and humidity; 
immersion specimens were kept in de-ionized water-filled glass tanks placed inside the temperature-humidity chambers. Two glass tanks with silicone-strip heating elements bonded to the outside were used to condition the IISN and HISN specimens (intermediate and high temperature salt water immersion). Traveler laminate panels made of the same prepreg and cured using the same protocol were used to study moisture uptake rates at different conditions. The traveler panels were manufactured with an aspect ratio of 100:1 and two thickness values. These were weighed throughout the environmental conditioning process to find the point at which diffusion stopped, or at least slowed sufficiently to meet the conditions defining equilibrium specified in ASTM D5229 [29].

It was initially assumed that the diffusion of moisture into the specimens could be considered Fickian. However, this may not be true of the material system being considered here, especially because the carbon fibre/epoxy laminates are a multi-phase system in which the toughened epoxy contains thermoplastic particles [30]. The behaviour of the diffusion specimens were therefore checked against the theoretical Fickian trend.The through-thickness diffusivity, $D_{z}$, was calculated by [29]:

$$
D_{z}=\pi\left(\frac{h}{4 M_{\infty}}\right)^{2}\left(\frac{M_{2}-M_{1}}{\sqrt{t_{2}}-\sqrt{t_{1}}}\right)^{2}
$$

where $h$ is the specimen thickness, $M_{\infty}$ is the equilibrium moisture content and $\left(M_{2}-M_{1}\right) /\left(\sqrt{t_{2}}-\sqrt{t_{1}}\right)$ is the slope of the initial linear part of the moisture content versus time curve. The value $M_{\infty}$ was read directly from the graph. An example calculation for one typical specimen using the raw mass data shown in Table 2 would yield:

$$
D_{z}=\pi\left(\frac{1.32}{4(1.22)}\right)^{2}\left(\frac{0.787-0}{13.0-0}\right)^{2}=0.0008 \mathrm{~mm}^{2} / \mathrm{hr}
$$

With this diffusivity value, it was then possible to plot the Fickian diffusion curve (1) and compare it to the experimental curves as shown in Fig. 2 for 10-ply specimens conditioned in salt water.

As can be seen in Fig. 2, Fick's diffusion model does not accurately represent the latter part of the diffusion process. Indeed, none of the data gathered in this study seems to suggest that the moisture absorption will reach the plateau that Fick's diffusion theory predicts. Whether the continuing increase in mass is indicative of a continuing damage to the structure by chemical interaction with the water, which in turn is allowing more water to be absorbed, or whether there are parts of the resin that absorb moisture at a much slower rate and over a longer period cannot be ascertained from the present study.

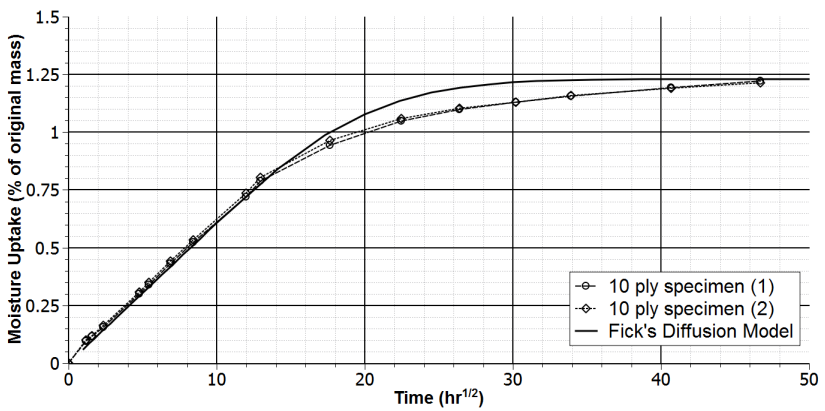

Figure 2. Comparison of Fick's theoretical diffusion curve and experimental curves for 10-ply specimens.

Table 1. Environmental conditioning matrix. Note that 5 specimens were exposed to each condition.

\begin{tabular}{ccccc}
\hline $\begin{array}{c}\text { Environmental } \\
\text { Condition } \\
\text { Designation }\end{array}$ & Temperature & $\begin{array}{c}\text { Type of Moisture } \\
\text { Exposure }\end{array}$ & Salinity & $\begin{array}{c}\text { Freeze Thaw } \\
\text { (Y/N) }\end{array}$ \\
\hline RTA & $\begin{array}{c}\text { Ambient lab } \\
\text { conditions }\end{array}$ & Ambient lab conditions & N/A & No \\
IVWN & $70^{\circ} \mathrm{C}$ & Vapour $-95 \%$ r.h. & Fresh water & No \\
& $82^{\circ} \mathrm{C}$ & Vapour $-95 \%$ r.h. & Fresh water & No \\
HVWN & $70^{\circ} \mathrm{C}$ & Immersion & Fresh water & No \\
IIWN & $82^{\circ} \mathrm{C}$ & Immersion & Fresh water & No \\
HIWN & $70^{\circ} \mathrm{C}$ & Immersion & Salt water & No \\
IISN & $82^{\circ} \mathrm{C}$ & Immersion & Salt water & No \\
HISN & & & & \\
\hline
\end{tabular}


Table 2. Raw data of mass measurements. Italics indicate calculated value. *calculated value of $D_{z},{ }^{* *}$ points used for slope calculation and $* * *$ indicates $M_{\infty}$

\begin{tabular}{ccccc}
\hline \multicolumn{2}{c}{ Specimen|Diffusivity $\rightarrow$} & \multicolumn{2}{c}{ Diff-10p-01 } & $8.13 \mathrm{E}-04^{*}$ \\
Date & Hours $^{1 / 2}$ & Mass & $\% \mathrm{D}$ & $\%$ Total \\
\hline $01 / 11 / 2011$ & $0^{* *}$ & 36.1130 & $W b$ & $0^{* *}$ \\
$+1: 20$ & $1.1{ }^{* *}$ & 36.1475 & 0.0955 & $0.0955^{* *}$ \\
$+2: 30$ & $1.6^{* *}$ & 36.1544 & 0.0191 & $0.115^{* *}$ \\
$+5: 35$ & $2.4^{* *}$ & 36.1686 & 0.0393 & $0.154^{* *}$ \\
$01 / 12 / 2011$ & $4.8^{* *}$ & 36.221 & 0.145 & $0.299 * *$ \\
$+29: 35$ & $5.4^{* *}$ & 36.2353 & 0.0395 & $0.339^{* *}$ \\
$01 / 13 / 2011$ & $6.9 * *$ & 36.2686 & 0.0919 & $0.431^{* *}$ \\
$01 / 14 / 2011$ & $8.4^{* *}$ & 36.3022 & 0.0926 & $0.524^{* *}$ \\
$01 / 17 / 2011$ & $12.0 * *$ & 36.3734 & 0.196 & $0.721 * *$ \\
$01 / 18 / 2011$ & $13.0 * *$ & 36.3972 & 0.0654 & $0.787^{* *}$ \\
$01 / 19 / 2011$ & 13.9 & & & \\
$01 / 24 / 2011$ & 17.7 & 36.4535 & 0.155 & 0.943 \\
$02 / 01 / 2011$ & 22.5 & 36.4914 & 0.104 & 1.05 \\
$02 / 09 / 2011$ & 26.4 & 36.5097 & 0.0502 & 1.10 \\
$02 / 18 / 2011$ & 30.2 & 36.5211 & 0.0312 & 1.13 \\
$02 / 28 / 2011$ & 33.9 & 36.5305 & 0.0257 & 1.16 \\
$03 / 21 / 2011$ & 40.7 & 36.5434 & 0.0353 & 1.19 \\
$04 / 12 / 2011$ & 46.7 & 36.5540 & 0.0290 & $1.22^{* * *}$ \\
\hline
\end{tabular}

\subsection{Mechanical Testing}

The procedure described in ASTM D5528 [31] was followed with a displacement rate of $2.0 \mathrm{~mm} / \mathrm{min}$, on a MTS table-top servo-hydraulic load test frame with an 890 $\mathrm{N}$ load cell with $\pm 1 \%$ precision. The load and displacement were measured every second and the data written to a file.

The specimens' edge was painted flat white and a scale with $1 \mathrm{~mm}$ graduations was bonded to it, just below the location of the (Teflon) pre-crack. A camera with macro lens was set up to observe the delamination tip through the white paint, and every time the tip crossed pre-determined graduations, a marker was entered in the file and the delamination length at that time was recorded on a separate sheet. Each marker therefore provided a data point with known delamination length, displacement and force. This was then used in the calculation of $G_{I C}$ as described in the next section. Each specimen was pre-cracked by following a loading/unloading cycle per ASTM D5528 before it was loaded again to obtain the measurements of fracture toughness.

\section{Data Reduction Procedure}

The raw data was analysed using a custom macro, which produced a plot of load versus displacement, created a table in which the manually-recorded delamination length and specimen measurements were entered, calculated the coordinates of the point of non-linearity (NL) and drew a $5 \%$ offset line on the load-displacement curve. For each specimen three methods for calculating the Mode I energy release rate were employed as outlined in ASTM D5528 [31].

All three calculation methods were used and compared, since the standard did not specifically endorse any one of them. Each method will be described below.

\subsection{Modified Beam Theory (MBT) Method}

A general relationship for strain energy release rate, $G_{C}$, can be given as:

$$
G_{c}=\frac{12 P^{2} a^{2}}{E b^{2} h^{3}}
$$

where $P$ is the applied load, $a$ is the instantaneous delamination length, $E$ is the Young's modulus, $b$ is the specimen width and $h$ is the specimen thickness. For DCB specimens, this may be further simplified to eliminate the need to separately measure the modulus $E$. This involves applying beam theory to find that the compliance, $C$, can be expressed as [27]:

$$
C=\frac{\delta}{P}=\frac{8 a^{3}}{b h^{3} E_{1 f}}
$$

where $\delta$ is the displacement of the loaded point and $E_{l f}$ is the flexural modulus in the longitudinal direction. From this we can deduce an expression for $E_{l f}$ :

$$
E_{1 f}=\frac{8 P a^{3}}{b \delta h^{3}}
$$

which can be substituted into (1) to give us the beam theory solution to calculate $G_{I C}$ from DCB data:

$$
G_{I C}=\frac{3 P \delta}{2 a b}
$$

This equation assumes that at the delamination tip, the boundary condition is zero rotation and displacement. In 
fact, neither degree of freedom is completely constrained, so that the above equation requires correction. It has been shown that adding a product, $\chi_{h}$, to the delamination length used in the above calculation corrects for this inaccuracy [32]. The value of $\chi$ is dependent on material properties and can be calculated from these, but it is also easily calculated from the data gathered during the DCB test. Because of the relationship:

$$
C^{\frac{1}{3}}=\left(\frac{8}{b h^{3} E_{1 f}}\right)^{\frac{1}{3}}(a+\chi h)
$$

a plot of $C^{1 / 3}$ versus $a$ will display the $\chi_{h}$ as the $x$-intercept of the curve [33], as shown in Fig. 3 based on data generated using a DCB specimen from this study. In ASTM D5528, this constant is called $\Delta$, so that the MBT calculation of $G_{I C}$ is:

$$
G_{I C}=\frac{3 P \delta}{2 b(a+|\Delta|)}
$$

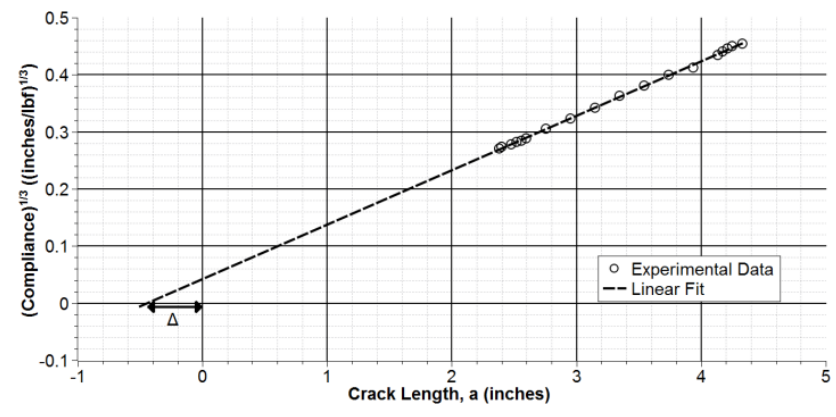

Figure 3. Graphical determination of $\Delta$.

\subsection{Compliance Calibration Method}

This technique simply assumes that the relationship between force and displacement is of the form [33]:

$$
P=\left(c a^{-n} \delta\right)
$$

which is a generalized version of the relationship from beam theory:

$$
P=\left(\frac{3}{2} E I a^{-3}\right) \delta
$$

By taking the logarithm of the generalized relationship with $m=P / \delta$ :

$$
\log (m)=\log (c)-n \log (a)
$$

one can see that plotting $\log (m)$, where $m$ is the stiffness, versus $\log (a)$ will yield a linear relationship if the initially-assumed general form is correct. From this plot, the constants $c$ and $n$ could be determined. Griffith's criterion for delamination propagation is given by [34]:

$$
\frac{\partial S}{\partial a}+\frac{\partial U}{\partial a}=0
$$

where $S$ is the free surface energy and $U$ is the strain energy. $\partial U / \partial a$ can be expressed conveniently by substituting (9) where needed:

$$
U=\frac{1}{2} P \delta
$$

The change in free surface energy per increment delamination length is:

$$
\frac{\partial S}{\partial a}=2 \gamma b
$$

where $\gamma$ is the surface energy density. Thus Griffith's criterion can be expressed, without requiring the value of the constant $c$, as [33]:

$$
\begin{aligned}
& 2 \gamma b-\frac{n P \delta}{2 a}=0 \\
& G=2 \gamma=\frac{n P \delta}{2 b a}
\end{aligned}
$$

This expression reduces to the MBT equation if $n=3$. The advantage of this method is its validity in situations where the "ideal" beam theory may be inaccurate, e.g., if the delamination is nonplanar or the specimen is not perfectly symmetrical.

\subsection{The Modified Compliance Calibration (MCC) Method}

The third and final method provided in ASTM D5528 is called the modified compliance calibration method. It is based on a previous finite element analysis (FEA) to establish the value of four constants $C_{0}, C_{1}, C_{2}$ and $C_{3}$, which were used to express the relationship between the non-dimensional ratio $a / h$ (delamination length-to-thickness ratio) and compliance $C$ as [35]:

$$
\frac{a}{h}=C_{0}+C_{1} \gamma+C_{2} \gamma^{2}+C_{3} \gamma^{3}
$$

where $\gamma=\left(b E_{L} C\right)^{1 / 3}$ is the normalized compliance, and $E_{L}$ is the modulus in the longitudinal direction $\left(=E_{11}\right.$ for unidirectional DCB specimens). With this relationship, the strain energy release rate was calculated to be [35]:

$$
G_{I}=\frac{3}{2 E_{L} h}\left(\frac{P}{b}\right)^{2}\left(\frac{\gamma^{2}}{C_{1}+2 C_{2} \gamma+3 C_{3} \gamma^{2}}\right)
$$

Simplifying the relationship between $a / h$ and $C$ to another empirical equation [31]: 


$$
\frac{a}{h}=A_{0}+A_{1} C^{\frac{1}{3}}
$$

then differentiating yields:

$$
\frac{1}{h}=\frac{1}{3} A_{1}\left(\frac{\partial C}{\partial a}\right)\left(C^{-\frac{2}{3}}\right)
$$

The general relationship for $G_{I C}$ in a double cantilever beam is given by:

$$
G=\frac{12 P^{2} a^{2}}{E b^{2} D^{3}}
$$

Substituting (19) into (20), yields:

$$
G_{I C}=\frac{P^{2}}{2 b}\left(\frac{\partial C}{\partial a}\right)=\frac{3 P^{2} C^{\frac{2}{3}}}{2 b h A_{1}}
$$

In this relationship, $A_{1}$ can be obtained by finding the slope of the line obtained when plotting $(a / h)$ versus $C^{I / 3}$, as shown in Fig. 4. The advantage of this method is stated to be its ability to calculate $G_{I C}$ values for a specimen configuration without having to measure the delamination length once the $A_{l}$ value is known. For the specimens in this study, the amount of degradation observed for specimens from the same condition was inconsistent, meaning that the $A_{1}$ values were not always close to each other. The method used for delamination measurement was also not as difficult to implement as the suggested method of ASTM D5528, so that avoiding delamination measurements was not particularly advantageous. Furthermore, the ASTM D5528 procedure requires one to find $A_{1}$ for every specimen, meaning that the main advantage stated in [36] is essentially lost.

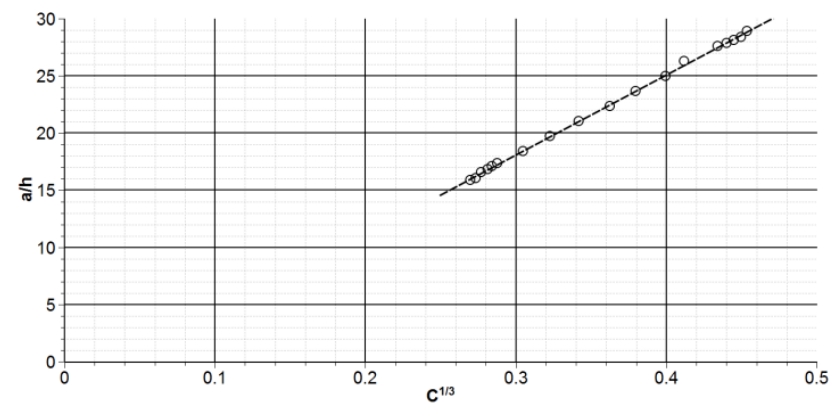

Figure 4. The slope of the line obtained by plotting $a / h$ versus $C^{1 / 3}$ gives the value of $A_{l}$ (the slope of the curve) to be used in the MCC method.

\section{Results}

\subsection{Onset Strain Energy Release Rate $G_{I C, 0}$}

Three methods for identifying the load and displacement that caused delamination onset to occur were employed in this study. As shown in Fig. 5 these are the visual onset of delamination growth (abbreviated "VIS"), the beginning of non-linearity of the $P-\delta$ curve ("NL") and $5 \%$ offset $/ \max$ load where $5 \%$ offset was defined to be the intersection of the curve with $5 \%$ increase in compliance from the linear portion of the $P-\delta$ curve with this curve.

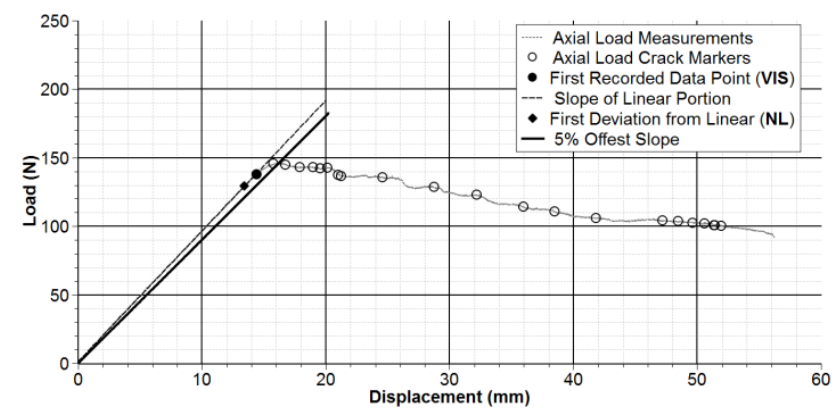

Figure 5. Summary of initiation values. Dashed line shows slope of linear portion of $P-\delta$ curve, NL is the point where $P-\delta$ deviates from linearity; $5 \%$ offset point is where the line having a $5 \%$ lower slope than the dashed line intersects $P-\delta$ and VIS is at the first marker, entered by the user as soon as delamination onset was observed.

Typical test results of onset and the propagation strain energy release rates of an unconditioned and conditioned bonded specimen subjected to Mode I loading are shown in Fig. 6 and Fig. 7, respectively. The conditioned specimen was subjected to $60^{\circ} \mathrm{C}, 95 \% \mathrm{RH}$ over 1000 hours. It can be seen that for both unconditioned and conditioned specimens, the $G_{I C, 0}$ values from VIS and $5 \%$ offset/max are similar, and are close to the propagation $G_{I C}$ measured on the adjacent location of the specimen. The $G_{I C, 0}$ calculated from NL was found to be significantly lower than other values. This trend was found to be consistent for other specimens as shown in Fig. 8 .

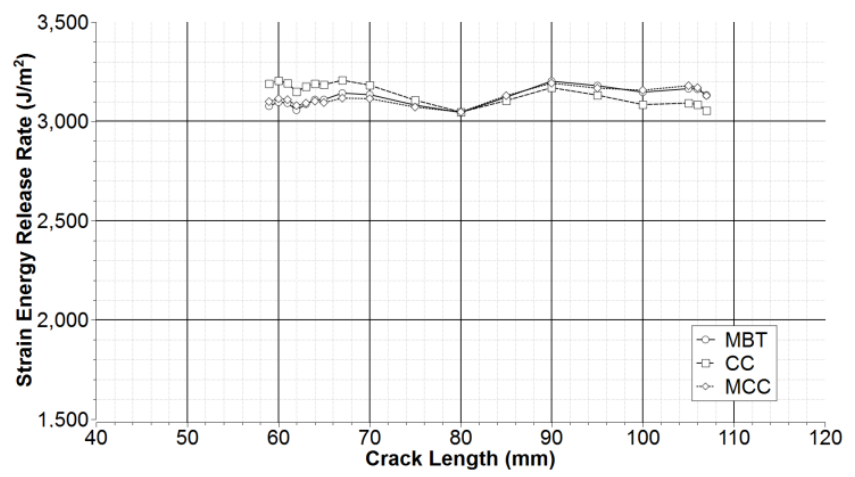

Figure 6. Typical fracture toughness results of an unconditioned bonded joint specimen under Mode I static loading.

The key difference between the onset delamination determined by nonlinearity point of the loading curve and other methods lies in the fact that nonlinearity is largely driven by flexural behaviour of the substrate itself and the rotation at the delamination tip, while the other two methods are directly associated with the event of fracture, either in the form of visual observation of delamination growth or a change in compliance. There are no consistent ways of determining NL points, and the values from the NL methods vary from user to user. From the perspective of 
delamination growth, delamination propagation is an extension of the onset. It is conceivable that for a pre-cracked bonded joint with no fibre bridging, change in failure mode or inconsistency in bond quality, there is a gradual change in $G_{I C}$, rather than a sudden jump as observed for NL method. For these reasons, onset $G_{I C, 0}$ values from VIS or $5 \%$ offset/max were considered to be representative. VIS or $5 \%$ offset/max are both fairly similar to each other for each specimen, which is particularly true of the case for the unconditioned specimens as shown in Fig. 8. For the conditioned specimens, $G_{I C, 0}$ from VIS were typically found slightly lower than the first propagation $G_{I C}$ value, while $5 \%$ offset/max values are often slightly higher. Since 5\% offset/max values are independent of operator experience, $G_{I C, 0}$ values from $5 \%$ offset/max are used for comparison purposes.

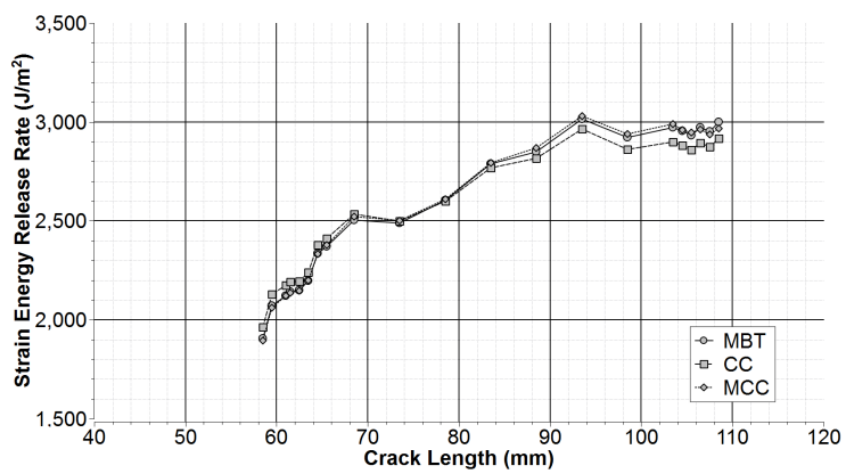

Figure 7. Typical fracture toughness results under Mode I loading of an environmentally aged bonded joint subjected to over 1000 hours at $60^{\circ} \mathrm{C}$, $95 \%$ RH (IVWN).

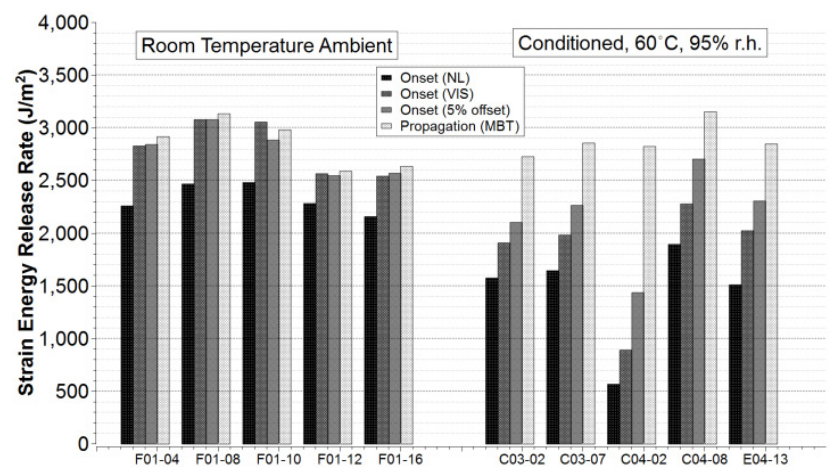

Figure 8. Onset strain energy release rates calculated based on NL, VIS, $5 \%$ offset/max and propagation $G$ in the adjacent location from onset of the unconditioned and conditioned specimens after conditioning at $60^{\circ} \mathrm{C}, 95 \%$ RH (IVWN).

\subsection{Energy Release Rate during Propagation $G_{I C}$}

Three methods (MBT, CC and MCC) were used to calculate strain energy release rate during propagation. As shown in Fig. 6 and 7, MBT, CC and MCC methods for $G_{I C}$ calculation yielded little difference, for both unconditioned and conditioned specimens. For the simplicity, $G_{I C}$ results from MBT were used for comparison in this study.

As per ASTM D5528, the load and displacement values were recorded for every $1 \mathrm{~mm}$ delamination length increments for the first $5 \mathrm{~mm}$, followed by load and displacement data at every $5 \mathrm{~mm}$, until the delamination has propagated for at least $45 \mathrm{~mm}$ from the tip, and again at every $1 \mathrm{~mm}$ increment of crack growth for the last $5 \mathrm{~mm}$ of delamination. This varying data frequency allows for an improved data capture of change in $G_{I C}$ in the region where $G_{I C}$ typically varies the most during propagation. A weighted average $G_{I C}$ during propagation was obtained taking into account the different increments of delamination growth, as shown below:

$$
G_{I C}=\frac{1}{\left(a_{(n+1)}-a_{1}\right)} \sum_{i=1}^{n} G_{I C, i}\left(a_{(i+1)}-a_{i}\right)
$$

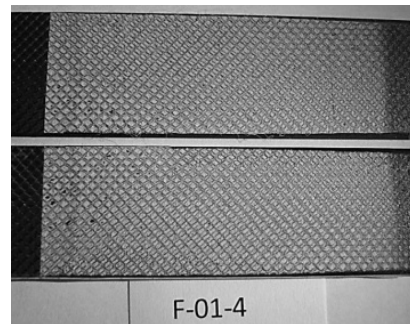

(a) $100 \%$ cohesive failure of unconditioned specimen

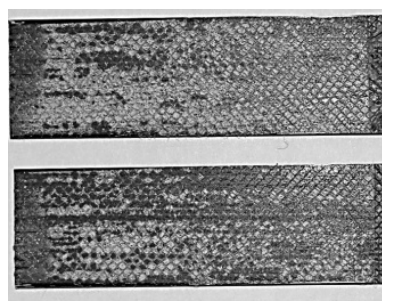

(b) Mixed failure mode of a conditioned specimen
Figure 9. Failure modes of typical (a) unconditioned specimens and (b) conditioned specimens.

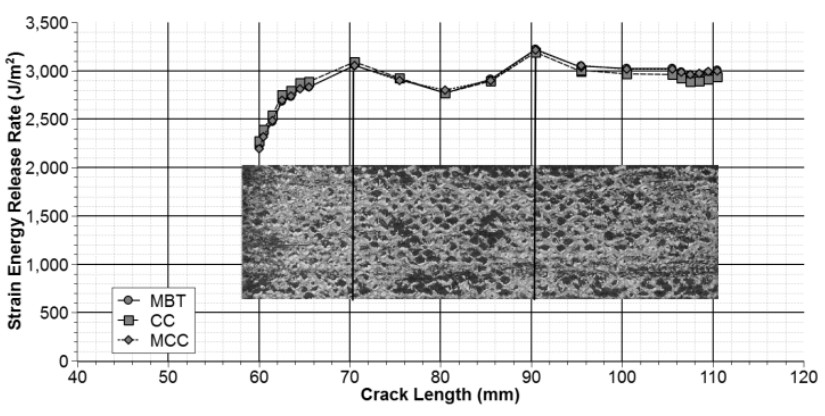

Figure 10. Areas of adhesive failure (black on photo) resulted in lower $G_{I C}$ values.

Where $a_{i}$ is the ith measured delamination length and $n$ is the total number of delamination length measurements during propagation and $G_{I C, i}$ is the calculated strain energy release rate at the $i t h$ measurement.

In general, the strain energy release rates of the unconditioned bonded specimen as shown in Fig. 8 are consistent within the test region of $50 \mathrm{~mm}$ delamination growth. This consistency in $G_{I C}$ correlates well with observed $100 \%$ cohesive mode for these unconditioned specimens (see Fig. 10(a)). In comparison, fracture toughness of an environmentally conditioned specimen varies significantly along the length of the specimen. All the conditioned specimens failed in a mixed cohesive/adhesive mode, as shown in Fig. 10(b). Comparing the specimens' fracture surfaces to their $G_{I C}$ graph provided some insight. In Fig. 9, the dips in $G_{I C}$ appear to match the areas where adhesive failure dominated, as evidenced on the photograph 
by the visibility of the black laminate. However, such correlation was not consistent for some other environmentally aged specimens. More study is needed to understand the environmental ageing mechanisms of bonded composite joints.

\subsection{Effect of Environmental Ageing on Fracture Toughness of Bonded Composite Joints}

Fig. 11 shows the overall comparison of average onset and propagation $G_{I C}$ values of specimens exposed to seven different environmental conditions. The standard error bars is generally high. In each condition, the fracture toughness varied greatly from specimen to specimen. Moreover, for environmentally aged specimens, the fracture toughness varied with delamination length. The variations in $G$ during propagation along the specimen delamination length add additional challenges to the data analysis and result comparison.

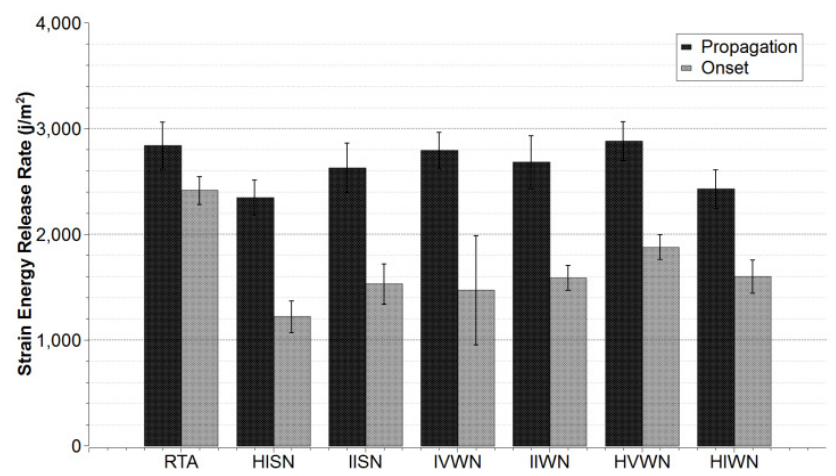

Figure 11. Overall comparison of onset and propagation strain energy release rates $G_{I C, 0}$ for all conditions. (Error bars represent $90 \% \mathrm{CI}$ ).

It can be seen in Fig. 11 that environmental ageing of all conditions led to an apparent reduction in onset $G_{I C}$ of the bonded joints under Mode I loading. Among the environmental factors, immersion appears to be the most significant, leading to a higher level of bond degradation than infusion. As compared to RTA baseline, reductions of $30 \%$ and $15 \%$ in onset $G_{I C}$ were observed for immersed and infused specimens, respectively. Other environmental factors such as salt and temperature did not seem to have an effect on onset fracture toughness in this study.

The propagation $G_{I C}$ value of each condition is calculated from the weighted average of each specimen taking into account the variation of $G_{I C}$ in the test section. The standard deviation as shown in Fig. 11 only reflect the deviation of each specimen from the group average, and the distribution of $G_{I C}$ in the test region of each specimens is not accounted for in this calculation. The comparisons show that there are two key factors affecting the overall propagation strain energy release rate: immersion and temperature. Immersion led to a reduction of $G_{I C}$ while infusion seems not have affected the overall average $G_{I}$. Such effect suggests that the degradation mechanism of immersion is different from that of infusion. The condition that has the most impact on fracture toughness of bonded joints in this study was found to be immersion at a higher temperature $82^{\circ} \mathrm{C}$, leading to the lowest $G$ for both onset and propagation. Salt was found to have no effect on the fracture toughness of the bonded joint specimens.

\section{Conclusions}

The MBT, CC and MCC data analysis methods yielded virtually the same strain energy release rates for the studied specimens. It was also noted that the $5 \%$ offset/max and VIS methods for determining onset strain energy release rate $G_{I C, 0}$ gave a better representation than NL point. In this study, MBT and 5\% offset/max were chosen to be the methods for data analysis and comparison.

Unconditioned specimens demonstrated constant fracture toughness with $100 \%$ cohesive failure mode. Not only is the fracture toughness stable over the $50 \mathrm{~mm}$ delamination growth range, the onset $G_{I C, 0}$ is the same as that of the propagation. In comparison, the fracture toughness of the environmentally aged specimens is highly variable during crack growth. The onset $G$ is consistently lower than that measured during propagation, and the $G_{I C}$ during propagation varies from location to location. This variation could be attributed partly to the change in observed change in failure mode.

Although there are large standard deviations among specimens, environmental ageing had an apparent impact on the fracture toughness of bonded joints. Among all the conditions, the most severe is the extended exposure to water immersion, fresh or salt, at a higher temperature of $82^{\circ} \mathrm{C}$. The test results show that among the environmental factors, infusion and immersion led to a reductions of $15 \%$ and $30 \%$ in onset $G_{I C, 0}$, respectively, as compared to unconditioned specimens. Immersion also led to reduction in propagation $G_{I C}$, showing that the degradation mechanism of immersion is different from that of infusion. The results also show that salt has no apparent effect on fracture toughness of bonded joints.

\section{Acknowledgements}

The authors would like to thank the technical staff of Carleton University and the National Research Council (NRC) Aerospace Portfolio for their support during the experimental portions of this work. Financial support for this project was provided in part by the Canadian Department of National Defence and the MITACS Accelerate Internship Program.

\section{REFERENCES}

[1] Baker, A., Dutton, S., Kelly, D.: Composite Materials for Aircraft Structures. AIAA Education Series, Reston, VA (2004). 
[2] Daniel, I.M., Ishai, O.: Engineering Mechanics of Composite Materials. Oxford University Press (1994).

[3] Gdoutos, E.E.: Fracture Mechanics: An Introduction. Springer (2005).

[4] Schijve, J. Fatigue of structures and materials in the 20th century and the state of the art. International Journal of Fatigue 25.8, 679-702 (2003).

[5] Schijve, J. Fatigue of structures and materials. Springer. (2003).

[6] FAA: Metallic Materials Properties Development and Standardization (MMPDS). Springfield, Va.: National Technical Information Service [distributor] (2003).

[7] Brinson, H.F., Brinson, L.C.: Polymer Engineering Science and Viscoelasticity Polymer Engineering Science and Viscoelasticity An Introduction. Springer (2008).

[8] Volynskii, A.L., Efimov, A.V., Bakeev, N.F.: Structural aspects of physical aging of polymer glasses. Polymer Science Series C. 49, 301-320 (2007).

[9] Dao, B., Hodgkin, J., Krstina, J., Mardel, J., Tian, W.: Accelerated aging versus realistic aging in aerospace composite materials. I. The chemistry of thermal aging in a low-temperature-cure epoxy composite. Journal of Applied Polymer Science. 102, 4291-4303 (2006).

[10] Damian, C., Espuche, E., Escoubes, M.: Influence of three ageing types ( thermal oxidation, radiochemical and hydrolytic ageing ) on the structure and gas transport properties of epoxy - amine networks. Polymer Degradation and Stability. 72, 447-458 (2001).

[11] FAA: Composite Materials Handbook - Volume 1 Guidelines for Characterization. (2002).

[12] Browning, C. E., G. E. Husman, and J. M. Whitney. Moisture effects in epoxy matrix composites. ASTM STP 617, 481-496, (1977).

[13] Bao, Li-Rong, and Albert F. Yee. Moisture diffusion and hygrothermal aging in bismaleimide matrix carbon fiber composites - part I: uni-weave composites. Composites Science and Technology, Vol. 16, 2099-2110 (2002).

[14] McBrierty, V.J., Martin, S.J., Karasz, F.E.: Understanding Hydrated Polymers: the Perspective of NMR. Journal of Molecular Liquids. 80, 179-205 (1999).

[15] Laplante, G., Lee-sullivan, P.: Moisture effects on FM300 structural film adhesive: Stress relaxation, fracture toughness, and dynamic mechanical analysis. Journal of Applied Polymer Science. 95, 1285-1294 (2005).

[16] Chatterjee, A., Jr, J.W.G.: Moisture Absorption Behavior of Epoxies and Their S 2 Glass Composites. Polymer. (2008).

[17] Xiao, G.Z., Delamar, M., Shanahan, M.E.R.: Irreversible Interactions Between Water and DGEBA / DDA Epoxy Resin During Hygrothermal Aging. Journal Of Applied Polymer Scienc. 449-458 (1996).

[18] Kinloch, A.J.: Interfacial Fracture Mechanical Aspects of Adhesive Bonded Joints-A Review. The Journal of Adhesion. 10, 93-219 (1979).

[19] Liljedahl, C.D.M., Crocombe, A.D., Wahab, M.A., Ashcroft, I.A.: Modelling the environmental degradation of adhesively bonded aluminium and composite joints using a CZM approach. International Journal of Adhesion and Adhesives. 27, 505-518 (2007).

[20] Zewi, I.G., Flashner, F., Dodiuk, H., Drori, L.: Durability of structural adhesive joints. International Journal of Adhesion and Adhesives. 4, 137-139 (1984).

[21] Taib, A., Boukhili, R., Achiou, S., Gordon, S., Boukehili, H.: Bonded joints with composite adherends. Part I. Effect of specimen configuration, adhesive thickness, spew fillet and adherend stiffness on fracture. International Journal of Adhesion and Adhesives. 26, 226-236 (2006).

[22] Parker, B.M.: The strength of bonded carbon fibre composite joints exposed to high humidity. International Journal of Adhesion and Adhesives. 1, 187-191 (1990).

[23] Parker, B.M.: Some Effects of Moisture on Adhesive-Bonded CFRP - CFRP Joints. Composite Structures. 6, 123-139 (1986).

[24] Randon, C., Komorowski, J. P., Lefebvre, D., and Roy, C. Analysis of variance of environmental effects on static tensile and compressive characteristics of carbon/epoxy laminates. Proceedings of the Tenth International Conference on Composite Materials, Whistler, BC, 1995.

[25] D'Almeida, J.R.M.: Effects of distilled water and saline solution on the interlaminar shear strength of an aramid/epoxy composite. Composites. 22, 448-450 (1991).

[26] Prolongo, S.G., Ureña, A.U.: Durability of Aluminium Adhesive Joints Bonded with a Homopolymerised Epoxy Resin. Journal Of Adhesion. 83, 1-14 (2007).

[27] Minford, J.D.: Comparative Aluminium Joint Evaluations in Varying Saltwater Exposure Conditions. Journal Of Adhesion. 18, 19-24 (1985).

[28] Hart-Smith, L.J.: Design of Adhesively Bonded Joints. Joining Fibre-Reinforced Plastics. 271-311 (1987).

[29] (ASTM): Standard Test Method for Moisture Absorption Properties and Equilibrium Conditioning of Polymer Matrix Composite Materials (ASTM D5229), (2004).

[30] Hill, S.J., Frulloni, E., LoFaro, C., Maskell, R.: Composite Materials and Their Use, (2010).

[31] (ASTM): Standard Test Method for Mode I Interlaminar Fracture Toughness of Unidirectional Fiber-Reinforced Polymer Matrix Composites (ASTM D5528), (2007).

[32] Hashemi, S., Kinloch, A.J., Williams, J.G.: The Analysis of Interlaminar Fracture in Uniaxial Fibre-Polymer Composites. Proceedings of the Royal Society A Mathematical Physical and Engineering Sciences. 427, 173-199 (1990).

[33] Berry, J.P.: Determination of Fracture Surface Energies by the Cleavage Technique. Journal of Applied Physics. 34, 62-68 (1963).

[34] Griffith, A.A.: The Phenomena of Rupture and Flow in Solids. Philosophical Transactions of the Royal Society A Mathematical Physical and Engineering Sciences. 221, 163-198 (1921).

[35] Kageyama, K., Kobayashi, T., Chou, T.: Analytical compliance method for Mode I interlaminar fracture toughness testing of composites. Composites. 18, 393-399 
(1987).

[36] Kageyama, K., Hojo, M.: Proposed Methods for Interlaminar
Fracture Toughness Tests of Composite Laminates. Proceedings of the 5th Japan-U.S. Conference on Composite Materials. pp. 227-234., Tokyo (1990). 